Nested or Networked? Future Directions for Ecological Systems Theory

Jennifer Watling Neal \& Zachary P. Neal

Michigan State University

This is the peer reviewed version of the following article:

Neal, J. W., \& Neal, Z. P. (2013). Nested or networked? Future directions for ecological systems theory. Social Development, 22(4), 722-737. https://www.doi.org/10.1111/sode.12018

which has been published in final form at the link above. This article may be used for noncommercial purposes in accordance with Wiley Terms and Conditions for Use of Self-Archived Versions.

At the end of this document, adapted versions of Figure 1 (Nested Model) and Figure 2 (Networked Model) are provided under a CC BY-NC-SA license. These adapted figures can be used in other publications and in dissertations provided this paper is cited using the above reference. It is not necessary to request permission to use these adapted figures. High-resolution PDF copies are available at https://osf.io/bd836/.

Jennifer Watling Neal, Department of Psychology, Michigan State University; Zachary P. Neal, Department of Sociology, Michigan State University. The authors contributed equally in the conceptualization and writing of this paper.

Correspondence concerning this article should be addressed to Jennifer Watling Neal, Department of Psychology, 316 W. Physics Rd., 127A Psychology Building, Michigan State University, East Lansing, MI 48824. Email: jneal@msu.edu. 


\begin{abstract}
Bronfenbrenner's ecological systems theory (EST) is among the most widely adopted theoretical frameworks for studying individuals in ecological contexts. In its traditional formulation, different levels of ecological systems are viewed as nested within one another. In this paper, we use Simmel's notion of intersecting social circles and Bronfenbrenner's earlier writing on social networks to develop an alternative "networked" model that instead views ecological systems as an overlapping arrangement of structures, each directly or indirectly connected to the others by the direct and indirect social interactions of their participants. We redefine each of the systems discussed by EST - micro, meso, exo, macro, and chrono - based on patterns of social interaction, and then illustrate how this alternative model might be applied in the classic context of the developing child. We conclude by discussing future directions for how the networked model of EST can be applied as a conceptual framework, arguing that this approach offers developmental researchers with a more precise and flexible way to think about ecological contexts. We also offer some initial suggestions for moving a networked EST model from theory to method.
\end{abstract}

Keywords: Ecological systems theory, social networks, development, context, Bronfenbrenner 


\section{Nested or Networked? Future Directions for Ecological Systems Theory}

Originally proposed by Bronfenbrenner $(1977,1979)$, ecological systems theory (EST) has been widely adopted by developmental psychologists interested in understanding individuals in context. Indeed, Google Scholar reveals that The Ecology of Human Development (Bronfenbrenner (1979), which first outlined EST, has been cited nearly 15,000 times as of September 2012. Conceptually, EST has been used to motivate a focus on setting level influences, guiding the development of contextual models to explain a range of phenomena including urban adolescent psychological and academic outcomes (e.g., Seidman, 1991), developmental risk and protective factors for substance use (e.g., Szapochnick \& Coatsworth, 1999), youth activity engagement (e.g., Rose-Krasnor, 2009), and family influences on gender development (e.g., McHale, Crouter, \& Whiteman, 2003). Empirically, developmental studies have used EST to identify contextual predictors or points of intervention that lie beyond the individual. For instance, studies of children and youth have often examined aspects of the peer, family, classroom/school, and neighborhood microsystems (e.g., Chipuer, 2001; Criss, Shaw, Moilanen, Hitchings, \& Ingoldsby, 2009; Gest \& Rodkin, 2011; Gifford-Smith \& Brownell, 2003; Seidman et al., 1995) or mesosystemic interactions between these microsystems (e.g., Durlak et al., 2007; Serpell \& Mashburn, 2012). However, in general, empirical exploration of exosystems and macrosystems in developmental studies applying an EST framework remains less frequent.

Although EST is widely recognized for underscoring the importance of interdependent and multi-level systems on individual development, the precise relationships of systems to one another remain elusive. Bronfenbrenner (1979) originally described ecological systems at different levels as nested within one another, giving rise to EST's classic graphic portrayal as a set of concentric circles. However, in this paper we argue that conceptualizing ecological systems as nested obscures the relationships between them. Instead, we argue that ecological systems should be conceptualized as networked, where each system is defined in terms of the social relationships surrounding a focal 
individual, and where systems at different levels relate to one another in an overlapping but non-nested way. Defining ecological systems in network terms not only provides greater theoretical clarity, but also yields a form of EST that more closely matches Bronfenbrenner's (1945) early recognition of the role of social networks in shaping development.

To build this argument, we begin by reviewing the traditional conceptualization of ecological systems as nested and highlight recent modifications to the theory. Then, drawing on Simmel's (1955 [1922]) notion of intersecting social circles, we discuss how ecological systems are better conceptualized as networked rather than nested. We illustrate the networked model of EST using the hypothetical example of a developing child. Finally, we discuss implications of this new conceptualization of ecological systems theory for future research.

\section{Ecological Systems as Nested: The Traditional Model}

Bronfenbrenner first proposed EST in a series of seminal publications in the 1970s and 1980s. We focus on the theory and definitions provided in The Ecology of Human Development (Bronfenbrenner, 1979), which are largely consistent with his earlier and later writing (Bronfenbrenner, 1977, 1986a, 1986b), and which are summarized in Table 1. Bronfenbrenner (1979) described the topology of the ecological environment as "a nested arrangement of structures, each contained within the next," which must be examined as an interdependent whole to fully understand the forces surrounding a developing individual (p. 22). This approach represented a sharp departure from more traditional approaches to developmental psychology of the day, which he derided as "the science of the strange behavior of children in strange situations with strange adults for the briefest possible periods of time" (p. 19). His initial articulation of EST identified four such structures, or systems - the microsystem, mesosystem, exosystem, and macrosystem - which are nested around a focal individual like a set of concentric circles, or as Bronfenbrenner suggested, a set of Russian dolls (i.e. a matryoshka doll). Thus, nearly all graphical depictions of EST rely on some variation of the concentric circles model shown in Figure 1. 
Bronfenbrenner (1979) viewed each system as arising from a setting, which he defined as "a place where people can readily engage in face-to-face interaction" (p. 22). At the lowest level of his nested hierarchy, microsystems are settings where the focal individual plays a direct role, has direct experiences, and has direct social interactions with others. Using the classic example of a developing child (see Figure 1), the family is a microsystem where the child plays a direct role (e.g., daughter, sibling), has direct experiences (e.g., enjoying family meals), and has direct social interactions with others (e.g., reading with mom, teasing baby brother). Mesosystems, within which microsystems are nested, include social interactions between two of the focal individual's settings. In our example, a mesosystem could include a meeting between a parent (from the child's family setting) and teacher (from the child's school setting) about a child's classroom behavior. This meeting represents a social interaction between members of the child's family microsystem and school microsystem. Exosystems, within which mesosystems are nested, include settings that influence the focal individual but in which the focal individual does not directly participate. An individual child generally does play a role in or have direct experiences in the education policy-making community, but educational policies nonetheless influence the child's classroom and school experiences. For example, a district decision to consolidate schools to save money may lead to larger classroom and school sizes, changing the microsystems in which children interact. Finally, macrosystems, within which exosystems are nested, include broad cultural influences or ideologies that have long-ranging consequences for the focal individual. For instance, societal views that place emphasis on teacher accountability and standardized test scores have led to policies such as the No Child Left Behind Act of 2001 that have implications for how children experience schooling. In addition to the four core systems of EST, Bronfenbrenner (1986a, 1986b) later introduced the chronosystem, a system reflecting change or continuity across time that influences each of the other systems. Transitions like a child's move from middle to high school or the onset of puberty are part of the chronosystem. 
Although nesting is a hallmark of EST, many of the systems in EST are simply not nested in nature. In our example of a developing child above, the family microsystem is nested inside the educational policy-making exosystem, but it makes little sense to view the former as a subset of the latter. Instead, these are two distinct systems, arising in distinct settings - one that contains the child and one that does not - that influence one another. Thus, we argue that viewing ecological systems as nested undermines the theoretical coherence and conceptual utility of EST. A focus on social interactions can help clarify how ecological systems are connected.

Social interactions are a key component of EST, and perhaps not surprisingly, as Bronfenbrenner (1945) was a pioneer in the earliest days of social network research. Bronfenbrenner (1979) clearly defined both the microsystem and mesosystem in terms of social interactions. For example, he noted that analysis of the microsystem "must take into account the indirect influence of third parties on the interaction between members of a dyad" because a focus on dyadic social interactions alone ignores the wider social context and is thus insufficient to capture the social forces bearing on the focal individual (proposition E; p. 68). Similarly, he defined mesosystems as arising from, among other types of interconnections, the "intermediate links in a social network" (p. 25). However, despite its explicit focus on social interactions, applications of EST typically have not focused their attention on patterns of social interactions. For example, Szapocznik and Coatsworth (1999) noted that the examination of mesosystems instead typically focuses on the interdependence of functioning across multiple domains in general terms (e.g., the effects of functioning at home on functioning at school). Thus, they call for a return to the exploration of social interactions that comprise both microsystems and mesosystems. In the current paper, we answer this call, and push it further by presenting not simply these two systems but the whole of EST through the lens of networks of social interactions.

\section{Ecological Systems as Networked: A Social Network Model}


Although not referenced in his early work on social networks (Bronfenbrenner, 1945) or formal articulation of EST (Bronfenbrenner, 1979), Bronfenbrenner's theoretical orientations bear a close resemblance to the work of Georg Simmel (1858 - 1918). For example, Bronfenbrenner's call for ecologically-minded psychologists to look beyond the dyad explicitly parallels Simmel's (1950 [1908]) extensive writing on the differences between dyads and triads, and his contention that socially interesting phenomena arise only in settings with more than two actors. Still more directly relevant to our reformulation of EST is Simmel's (1955 [1922]) essay on social circles, which closely resemble what Bronfenbrenner called systems. Simmel recognized that when circles/systems are concentrically arranged, "participation in the smallest of these...already implies participation in the larger" (p. 147), and thus that the forces impacting a person's development are entirely determined by the smallest circle/system in which he or she participates. Simmel and other early social theorists (e.g. Durkheim 1984 [1893], McPherson 2004) viewed such an arrangement of social circles as the hallmark of a 'primitive' society with a relatively undifferentiated social structure. For example, in feudal society governed by tradition and custom, membership in a particular family determined one's trade, and one's trade determined one's friends (i.e. other guild members) and one's place of residence. Thus, family membership - the smallest social circle/system - fully determined the ecological forces impacting one's development.

In contrast, Simmel hypothesized that the range of forces impacting a person's development "will be greater when the [circles] which influence him are juxtaposed than if they are concentric" (p. 147). Bronfenbrenner offered the same hypothesis more than 50 years later, noting that "the developmental status of the individual is reflected in the substantive variety and structural complexity of the...activities which she initiates" (Bronfenbrenner, 1979, p. 55). Clearly, both Simmel and Bronfenbrenner appreciated that the ecological influences brought to bear on individuals are far more complex than a simple nested/concentric configuration of social circles/systems could adequately 
capture. However, simply redrawing the traditional graphic representation of EST using intersecting, rather than nested or concentric, circles does little to clarify the underlying theoretical model. For this job, we turn to social networks and the importance of patterns of social interaction, with which both Simmel and Bronfenbrenner were intimately familiar.

The fundamental building block of EST is the setting, thus any attempt to re-theorize EST must begin here. For Bronfenbrenner (1979), "a setting is a place where people can readily engage in face-to-face interaction" (p. 22, emphasis added), and thus has a primary spatial dimension, and a secondary interactional dimension. However, when it comes to forces that influence individuals' development, are interactional factors really secondary to spatial ones? Compare the developmental consequences of couple A interacting lovingly at home, and couple B interacting lovingly on vacation. A social network, or structuralist, perspective contends that common forces are likely to shape the development of these two couples because they are engaged in common patterns of interaction, even if in different locations. Similarly, compare the developmental consequences of couple A interacting lovingly at home, and couple $\mathrm{C}$ fighting at home. Here, a network perspective contends that different forces are likely to shape the development of these two couple because they are engaged in different patterns of social interaction, even if in the same location. Thus, although we continue to view settings as the fundamental building block of EST, adopting a network perspective we offer a definition that mirrors but inverts Bronfenbrenner's by focusing primary attention of patterns of social interaction: $a$ setting is a set of people engaged in social interaction, which necessarily occurs in, and is likely affected by the features of, a place (see Table 1). This focus on patterns of social interaction has previously been advocated in the specific context of EST by Szapocznik and Coatsworth (1999), more generally in community psychology by Seidman (1988), and across the social sciences since the initial sociometric work of Moreno (1934). Notably, although our conception of a setting places primary attention on the 
patterns of social interaction, it does not reject that spatial factors may nonetheless play an important role.

Having defined settings as sets of interacting people, we begin our networked reformulation of EST by observing that the ecological environment is an overlapping arrangement of structures, each directly or indirectly connected to the others by the direct and indirect social interactions of their participants. This definition not only highlights that systems are not necessarily nested within one another, but also clarifies that it is individuals' patterns of social interactions with other another that determine how systems relate to one another. Moreover, it allows each type of system to be precisely defined in terms of patterns of interaction.

Figure 2 illustrates a hypothetical pattern of social interactions - that is, a social network among nine people (labeled A thru I), with the focal individual represented by the shaded circle in the center. Each set of people who all interact with one another - that is, a setting - is enclosed by a dashed circle. For example, persons A thru D all interact with one another and thus constitute a setting. From these settings, it is possible to identify ecological systems using definitions that closely parallel those originally proposed by Bronfenbrenner. First, a microsystem is a setting - or set of people engaged in social interaction - that includes the focal individual. In this example, there are three microsystems: one on the left composed of $\mathrm{A}-\mathrm{B}-\mathrm{C}-\mathrm{D}$, one on the right composed of $\mathrm{A}-\mathrm{E}-\mathrm{F}-\mathrm{G}$, and one that overlaps with these two composed of A-D-E. Second, a mesosystem is a social interaction between participants in different settings that both include the focal individual. Here, the relationship between D, who participates in the setting on the left, and E, who participates in the setting on the right, is a mesosystemic interaction. Finally, an exosystem is a setting - or set of people engaged in social interaction - that does not include, but whose participants interact directly or indirectly with, the focal individual. This example contains one setting, composed of $\mathrm{G}-\mathrm{H}-\mathrm{I}$, that is an exosystem. Together, these individuals constitute 
an interactional setting does not contain the focal individual, but whose participants are each directly (e.g. person $\mathrm{G}$ ) or indirectly (e.g. persons $\mathrm{H}$ and I, by two steps) connected to the focal individual.

As the simple example in Figure 2 illustrates, adopting this approach highlights the intersecting, non-nested character of ecological systems. For example, different microsystems can overlap when they involve distinct sets of individuals participating in different settings. Similarly, the mesosystem is ipso facto a social interaction that requires the intersection of two microsystems.

However, by more robustly specifying the relationships between systems at different ecological levels, the networked model of EST also expands the utility of the theory by making it possible to consider the ecological environment from the perspective of different focal individuals. Suppose the simple social network shown in Figure 2 represented the entire social universe. If person A is the focal individual, as the figure illustrates, this person's development is influenced by three microsystems, one mesosystem and one exosystem. However, applying the same network-based definitions of ecological systems, it is possible to consider what systems shape the development of, for example, person C instead. In contrast to person A, person C's development is influenced by one microsystem (A-B-CD), no mesosystems, and three exosystems (A-D-E, A-E-G-F and G-H-I). This highlights that the specific nature and configuration of ecological systems influencing the development of an individual depends on, must be considered from, the perspective of the focal individual. Although A-E-G-F is a microsystem for person $\mathrm{A}$, it is an exosystem for person $\mathrm{C}$.

To this point, we have considered only the first three of EST's five systems. The macrosystem and chronosystem are not built from settings, but rather refer to forces that shape the patterns of social interactions that define settings. First, the macrosystem is the set of social patterns that govern the formation and dissolution of social interactions between individuals, and thus the relationship among ecological systems. For example, the social pattern known as homophily refers to individuals' tendency to interact with others who share a social status (e.g. race, gender, etc.) or who share an attitude or value orientation (e.g. 
commitment to social justice) (Lazarsfeld \& Merton, 1964; McPherson, Smith-Lovin, \& Cook, 2001). Similarly, transitivity refers to the tendency for two individuals with a common acquaintance to interact as they are brought together in common settings, by common values, or with common goals (Feld, 1981). As enduring patterns in human social interaction, homophily and transitivity significantly determine the structure of social networks, and thus the configuration of ecological systems surrounding a focal individual. In addition to structural tendencies like homophily and transitivity, broad forces like legal, political and cultural systems typically associated with the macrosystem also manifest their effects in the structure of social networks by shaping with whom one may, or is likely to, interact. Second, the chronosystem is the observation that patterns of social interactions between individuals change over time, and that such changes impact the focal individual, both directly and by altering the configuration of ecological systems surrounding him/her. The modeling and analysis of dynamic social networks is an emerging area of study, with some seeking to understand how networks evolve endogenously (Robins, Pattison, Kalish, \& Lusher, 2007), and others exploring how both natural (e.g. social development; Schaefer, Light, Fabes, Hanish, \& Martin, 2010; Veenstra \& Dijkstra, 2011) and intentional (e.g. interventions; Hawe, Sheill, \& Riley, 2009) exogenous forces can modify network structures.

\section{A Hypothetical Example}

To concretely illustrate ecological systems as networked, in this section we return to the classic example of a developing child used in Bronfenbrenner's (1977, 1979, 1986a, 1986b) original formulation of EST. As noted earlier, EST has traditionally viewed the child as positioned at the center of a series of nested ecological systems leading from those most immediate to the child (e.g., microsystems such as the family and school) to those most distal (e.g., macrosystemic forces such as societal views on education) (see Figure 1). However, conceptualizing EST in terms of social networks leads to a strikingly different arrangement of the ecological systems surrounding the child. Following Simmel's (1955 [1922]) conception of social circles, the child appears as part of an overlapping or 
intersecting set of ecological systems that are linked to one another through direct and indirect social interactions (see Figure 3).

In Figure 3, the focal child in our example participates in two different settings. The setting on the left, composed of the daily familial interactions of the child, mother, father, and sibling can be identified as a microsystem because the focal individual (i.e. the child) is a participant. Moreover, it can be identified specifically as a family microsystem given the specific identities and roles of its participants and the content of their social interactions. The setting on the right, composed of the social interactions between the child, teacher, coach, and principal can also be identified as a microsystem, again because the child is a participant, and more narrowly as a school microsystem given the identities and roles of its participants and the content of their social interactions. Both the family and school settings have long been recognized as key microsystems impacting the children's development. For example, researchers have studied social processes within the family including social support, hassles, parentchild relationships, and sibling relationships (e.g., Bokhorst, Sumter, \& Westenberg, 2010; Bronfenbrenner, 1986a; McHale et al., 2003; Seidman et al., 1995). Similarly, they have also examined social processes within schools including teacher-student relationships (e.g., Hamre, Pianta, Downer, \& Mashburn, 2008; Howes, 2000; Pianta, 1999; Troop-Gordon \& Kopp, 2011), teacher practices (e.g., Gest \& Rodkin, 2011; Cappella \& Neal, 2012), school social support (e.g., Bokhorst et al., 2005; Seidman et al., 1995) and peer interactions (see Gifford-Smith \& Brownell, 2003 for review). However, although previous research has typically defined the boundaries and participants of microsystems in advance, a networked model of EST relies on the actual social interactions within the child's life to locate them. This approach, focusing on actual patterns of social interaction rather than a priori expectations, mirrors Wellman's (1988) recommendation that the social world be viewed as “composed of networks, not groups" (p. 37). 
One social interaction, between the child's mother and teacher, bridges between these two microsystems. Because this social interaction occurs between participants in different settings that both include the focal individual, it can be identified as a mesosystem. More specifically, given the context of this cross-setting social interaction in our example, we identify it as a school/family mesosystem. Such family-school relationships may occur when parents or guardians meet with teachers at school conferences, volunteer in the classroom, or receive regular notes from teachers about their child's progress, and are a main focus in educational practice and research (e.g., Epstein, 1995; Kelley, 1990; Serpell \& Mashburn, 2012). In our example, perhaps the child's mother regularly speaks with the teacher over the phone about her daughter's progress in class and has been able to build a relationship with the teacher through this experience. Defining the mesosystem as a relationship that bridges two microsystems allows researchers to study direct social interactions, which have been described as an "understudied phenomenon" in assessments of the mesosystem (Szapochnick \& Coatsworth, 1999, p. 346).

Figure 3 also contains a setting - that is, a set of people engaged in social interaction - that does not include the child. This setting, located in the upper right corner, is composed of the social interactions among three actors in the educational policy area: the superintendent, mayor, and principal. Because the child does not actually participate in this setting, but nonetheless directly or indirectly interacts with its participants - here, directly with the principal, and indirectly with the superintendent and mayor via the principal - the setting can be identified as an exosystem. More specifically, given the roles of this setting's participants and the content of their social interactions, we identify it as the education policy exosystem. The role of school administrators, government officials, and policymakers in indirectly shaping children's development has often been explored in educational research (e.g., Daly \& Finnigan, 2010; Spillane \& Thompson, 1997). For example, the mayor may start a healthy eating campaign in the city and may work with the superintendent and principal to eliminate 
unhealthy foods in the school cafeteria. These cafeteria changes will impact on the focal child's school microsystem, and may lead her to choose healthier options like fruits or vegetables at lunchtime. However, the focal child is only indirectly connected to the setting responsible for these changes. The configuration of the microsystems, mesosystem, and exosystem as intersecting in the networked model of EST illustrated by Figure 3 is notably different from their configuration as nested in the more traditional model of EST illustrated by Figure 1. For example, the traditional model of EST views microsystems as nested within mesosystems. However, it makes little sense to suggest that the family or school settings are nested within the mother-teacher relationship. To be sure, the family and school microsystems are affected by the mother-teacher relationship, but they are not inside of it. Instead, as the networked model highlights, mesosystemic interactions like those between a mother and teacher can more properly be understood as existing between intersecting microsystems. Similarly, the traditional model views the mesosystem as nested within the exosystem. Again, it makes little sense to suggest that the mother-teacher relationship is nested within the education policy system. In fact, in our example, none of the participants in the mesosystem (i.e. the mother and teacher) are participants in the exosystem (i.e. the principal, superintendent, and mayor). The networked model of EST highlights that mesosystems and exosystems are distinctly different types of settings that could, but are not required to, overlap. Viewing ecological systems as a series of settings that intersect and overlap to varying degrees, as the networked model does, provides EST greater flexibility by not rigidly specifying that each system is wholly nested within the next, and also allows understandings about the relationships between different systems to more closely mirror reality.

Although Figure 3 does not include an overt illustration of the macrosystem or chronosystem, a networked model of these two systems can still be applied to the developing child in our example. Identification of macrosystemic factors that influence the focal child involves considering the social patterns that influence the formation and dissolution of social interactions between individuals in the 
child's social world. For example, examining Figure 3, the social pattern of homophily might be useful for explaining the mesosystemic relationship between the child's mother and classroom teacher. Perhaps the mother and teacher are connected because they share a viewpoint - for example, that education is important - which leads to their increased social interaction and a strengthened relationship between them. Similarly, the social pattern of transitivity might help explain the relationship between the school principal and mayor in the educational policy exosystem. The superintendent's job is likely to require social interaction with both the principal and mayor. Because both the principal and the mayor interact regularly with the superintendent, transitivity suggests that social interaction is likely to occur directly between the principal and mayor as well, perhaps through joint meetings to discuss the implementation of a healthy foods initiative.

The macrosystem is frequently associated with legal, political, and cultural phenomena, which may appear lacking in this networked perspective. However, because such macrosocial phenomena directly impact how individuals interact with one another, the networked perspective does not exclude their consideration. Several examples serve to illustrate. First, consider the effect of a legal ruling requiring school desegregation (e.g. Brown v. Board of Education). Because such a ruling will alter the demographic composition of schools, it will directly impact the level of diversity of the focal child's network. Second, consider the effect of a shift in the political structure of the school board, from one constituted by appointment to one constituted by democratic election. Such a shift may require members of the education policy exosystem to expand their networks in search of electoral support, thereby potentially altering the size of the exosystem and its relationship to the other systems. Finally, consider the effect of cultural practices surrounding gender, and specifically the difference between a culture that favors gender-separate education from one that favor coeducational institutions. Such a cultural value will directly impact the potential and actual gender homophily observed in the focal child's network. The networked model of EST may be unable to capture all possible macrosocial 
phenomena, but likely no model could rise to this task. However, it can capture macrosocial phenomena to the extent that their effects are reflected in patterns of individuals' social interactions. We believe this is sufficient because macrosocial phenomena that do not affect individuals' social interactions are not likely to have significant or observable impacts on individual development.

The chronosystem reflects changes in patterns of social interaction over time and can also be applied to our hypothetical example of the developing child. Life transitions may shape and restructure the social interactions in the focal child's life. As the focal child's own patterns of social interaction change, and as the patterns of social interaction of those indirectly connected to the focal child change, the location and relationship of the ecological systems surrounding the focal child will shift. For example, at present, the focal child's sibling is still a toddler and has not yet started attending school. However, within the next few years, he will start kindergarten in the same school as his sister, potentially leading to new mesosystemic interactions that bring the school and family microsystems closer together. Moreover, consistent with developmental research (e.g., Berndt, 1982; Larson, Richards, Moneta, Holmbeck \& Duckett, 1996), as our focal child moves into adolescence, she may spend less time interacting family members and more time interacting with peers at school or in the neighborhood, shifting relationships within, or even prompting the formation of new, microsystems.

Finally, Figure 3 clearly illustrates how the specific nature and configuration of ecological systems influencing the development of an individual must be considered from the perspective of that individual. The focal child described in this example is shaped by a family microsystem, a school microsystem, a school-family mesosystem, and an education policy exosystem. However, considering the social world outlined in Figure 3 from her sibling's perspective leads to a different configuration. Although, the sibling is part of the same family microsystem as his sister, he is still a toddler and is not currently enrolled in school. Thus, from his perspective, the school and the educational policy settings are both exosystems, to which he is indirectly connected through his sister. He does not directly 
participate in either the school or educational policy settings, but may still be influenced by his sister to eat his fruits and vegetables due to healthy eating habits that she picked up from her school's new cafeteria policy.

\section{Future Directions for the Networked Model of EST}

In this paper, we have argued that the ecological systems outlined in EST are more usefully conceptualized as networked rather than nested. In contrast to EST's traditional view of ecological systems as concentrically arranged in a nested configuration, a networked model of EST views ecological systems as overlapping and connected through direct and indirect social interactions. As a conceptual model of the forces impacting individuals' development, the networked approach offers a number of advantages. First, it shifts the focus of attention away from where individuals interact and toward how and with whom they interact, which is essential to the extent that human development is a social process. Second, it allows researchers to examine more complex relationships among ecological systems, including a multiplicity of different microsystems that only partially overlap, and mesosystems and exosystems that bridge these microsystems. Third, it offers a way to more fully incorporate Bronfenbrenner's (1979) “recognition that environmental events and conditions outside any immediate setting containing the person can have a profound influence on behavior and development" (p. 18, emphasis added). Although many applications of EST focus primarily on the microsystem, it is not for researchers' lack of interest in higher-order systems, but rather for the daunting ambiguity of these systems. The networked model provides more theoretically consistent definitions that clearly specify not only what each system of composed of, but also how each system is related to the others. Finally, by more explicitly incorporating social networks into EST, it offers a path for moving from theory to method.

From theory to method 
As a theory, EST only specifies constructs, but does not necessarily specify how those constructs should be empirically operationalized in practice. Thus, both the traditional nested model and our proposed networked model rely on the construct of `settings' as the fundamental building block of ecological systems, but neither model offers a precise empirical operationalization. However, by focusing attention of patterns of social interaction, the networked model offers the possibility of using the precise tools of social network analysis to move EST from a theory to a method. A complete discussion and formal validation of network analytic operationalizations of the setting construct would go beyond the scope of this paper, but we briefly consider some possibilities that may be useful in the future translation of our theoretical reformulation of EST into a measurement methodology.

We have defined a setting as a set of people engaged in social interaction. Although such a broad definition is appropriate for a theoretical construct, it is too ambiguous for an empirical operationalization, leaving open questions about the necessary amount of social interaction and the delineation of members from non-members. However, the social network concept of a clique offers some precise answers to such questions, and thus some potential operational definitions of a setting. Moreover, just as settings come in many forms - some are small and intimate, while others are large and fluid - the network concept of clique has multiple operational definitions. Figure 4 illustrates some conceptions of a network clique that may be useful for operationalizing the construct of settings in EST. The simplest and most restrictive, the maximal complete subgraph, defines a clique as a set of people in which every member directly interacts with every other member (Scott, 2000; Wasserman \& Faust, 1994). In Figure 4, there are three examples of a maximal complete subgraph: A-B-C, D-E-F, and $\mathrm{X}-\mathrm{Y}-\mathrm{Z}$. This is implicitly the operationalization of setting we have used in the examples discussed above. However, in practice this conception of a clique might be most appropriate for 
defining a small setting, such as a family, where all members are likely to directly interact with one another, whereas more inclusive conceptions may be necessary for operationalizing larger settings.

An $\mathrm{N}$-clique is a set of people in which every member is no more than $\mathrm{N}$ steps away from every other member, and thus in which members interact with one another either directly or indirectly through just a few intermediaries (Scott, 2000; Wasserman \& Faust, 1994). This conception might be appropriate for settings larger than a family, but still sufficiently compact that all participants interact at least indirectly with one another, such as a school classroom or an office workplace. Finally, a K-core is a subset of people in which every member is directly connected to at least $\mathrm{K}$ other members, and thus in which members interact with some minimum number of other members (Scott, 2000; Wasserman \& Faust, 1994). This conception is the most inclusive, and thus might be appropriate for very large settings in which most participants do not directly interact with one another, but where social interaction with just a few others is sufficient for a sense of belonging, such as a school district or political party.

Using network cliques to define settings is not a panacea for dealing with the complexity of ecological environments. Such an approach still requires researchers to consider several questions, including which conception of a clique is appropriate in a given context, and under what circumstances a network clique can be interpreted as a setting. However, for the goal of pushing EST from a purely conceptual model toward a robust method, we believe these are the right questions for researchers to be asking. When seeking to understand the content and organization of the ecological environment surrounding a developing person, they focus attention on directly measurable features of the environment and allow ecological systems to emerge from the data, rather than to be defined in advance based on a priori assumptions. Additionally, these questions highlight a path for the future development of EST as a method by suggesting parallels between the concept of an ecological 
environment and the vast empirical literature on clique analysis (e.g. Everett \& Borgatti, 1998) and community detection (e.g. Fortunato, 2010).

\section{Summary and Conclusions}

In this paper, we have sought to revisit Bronfenbrenner's (1979) ecological systems theory, which is perhaps one of the most influential theories guiding developmental research. We contend that although EST is traditionally described using a nested systems metaphor, it is more usefully viewed as an overlapping configuration of interconnected ecological systems. Thus, we present an alternative 'networked' model of EST that defines ecological systems in terms of patterns of social interaction. This approach brings the relational perspective present in Bronfenbrenner's (1945) earliest writing to EST and offers many benefits. First, it reconceptualizes settings, drawing attention to social interactions as the building blocks of ecological systems. Second, it clarifies how ecological systems are related to one another, highlighting that they are not necessarily nested, but instead overlap in complex ways. Finally, it establishes the potential for a direct linkage between EST as a theory and social network analysis as a method, thereby paving the way for more precise operationalization and measurement for research adopting an EST perspective, but also for more theoretically informed applications of network analysis. As a new conceptual framework for understanding what ecological systems are and how they relate to one another, we hope the networked model of EST offers developmental researchers and others a useful way to think about ecological environments, and that this paper represents merely an initial step in its further development. 


\section{References}

Berndt, T. (1982). The features and effects of friendship in early adolescence. Child Development, 53, $1447-1460$.

Bokhorst, C.L., Sumter, S.R., \& Westenberg, P.M. (2010). Social support from parents, friends, classmates, and teachers in children and adolescents aged 9 to 18 years: Who is perceived as most supportive? Social Development, 19(2), 417-426. doi: 10.1111/j.1467-9507.2009.00540.x

Bronfenbrenner, U. (1945). The measurement of sociometric status, structure, and development. New York: Beacon House.

Bronfenbrenner, U. (1977). Toward an experimental ecology of human development. American Psychologist, 32(7), 513-531.

Bronfenbrenner, U. (1979). The ecology of human development: Experiments by nature and design. Cambridge, MA: Harvard University Press.

Bronfenbrenner, U. (1986a). Recent advances in research on the ecology of human development. In R.K. Silbereisen, K Eyferth, \& G. Rudinger (Eds.), Development as action in context: Problem behavior and normal youth development (pp. 287-309). Heidelberg and New York: Springer.

Bronfenbrenner, U. (1986b). Ecology of the family as a context for human development: Research perspectives. Developmental Psychology, 22, 723-742.

Cappella, E. \& Neal, J.W. (2012). A classmate at your side: Teacher practices, peer victimization, and network connections in urban schools. School Mental Health, 4, 81-94. doi: 10.1007/s12310012-9072-2.

Chipuer, H.M. (2001). Dyadic attachments and community connectedness: Links with youths' loneliness experiences. Journal of Community Psychology, 29, 429-446.

Criss, M.M., Shaw, D.S., Moilanen, K.L., Hitchings, J.E., \& Ingoldsby, E.M. (2009). Family, neighborhood, and peer characteristics as predictors of child adjustment: A longitudinal 
analysis of additive and mediation models. Social Development, 18(3), 511-535. doi:

10.1111/j.1467-9507.2008.00520.x.

Daly, A. \& Finnigan, K. (2010). The ebb and flow of social network ties between district leaders under high-stakes accountability. American Educational Research Journal, 48, 39-79. doi: 10.3102/0002831210368990.

Durkheim, E. (1984 [1893]). The Division of Labor in Society, W. D. H. (Trans.). New York: The Free Press.

Durlak, J.A., Taylor, R.D., Kawashima, K., Pachan, M.K., DuPre, E.P., Celio, C.I., Berger, S.R., Dymnicki, A.B., \& Weissberg, R.P. (2007). Effects of positive youth development programs on school, family, and community systems. American Journal of Community Psychology, 39, 269-286. doi: 10.1007/s10464-007-9112-5.

Epstein, J.L. (1995). School/family/community partnerships: Caring for the children we share. Phi Delta Kappan, 76, 701-712.

Everett, M. G., \& Borgatti, S. P. (1998). Analyzing clique overlap. Connections, 21, 49-61.

Feld, S. (1981). The focused organization of social ties. American Journal of Sociology, 86, 1015-1035.

Fortunato, S. (2010). Community detection in graphs. Physics Reports, 488, 75-174. doi:10.1016/j.physrep.2009.11.002

Gest, S.D., \& Rodkin, P.C. (2011). Teaching practices and elementary classroom peer ecologies. Journal of Applied Developmental Psychology, 32(5), 288-296. doi:10.1016/j.appdev.2011.02.004.

Gifford-Smith, M.E., \& Brownell, C.A. (2003). Childhood peer relationships: social acceptance, friendship, and peer networks. Journal of School Psychology, 41, 235-284. doi: 10.1016/S00224405(03)00048-7. 
Hamre, B.K., Pianta, R.C., Downer, J.T., \& Mashburn, A.J. (2008). Teachers’ perceptions of conflict with young students: Looking beyond problem behaviors. Social Development, 17(1), 115-136. doi: 10.1111/j.1467-9507.2007.00418.x.

Hawe, P., Shiell, A., \& Riley, T. (2009). Theorising interventions as events in systems. American Journal of Community Psychology, 43, 267-276. doi: 10.1007/s10464-009-9229-9.

Howes, C. (2000). Social-emotional classroom climate in child care, child-teacher relationships and children's second grade peer relations. Social Development, 9(2), 191-204.

Kelley, M.L. (1990). School-home notes: Promoting children's classroom success. New York: Guilford Press.

Larson, R.W., Richards, M.H., Moneta, G., Holmbeck, G., \& Duckett, E. (1996). Changes in adolescents' daily interactions with their families ages 10 to 18: Disengagement and transformation. Developmental Psychology, 32, 744-754.

Lazarsfeld, P. F., \& Merton, R. K. (1964). Friendship as social process: a substantive and methodological analysis. In M. Berger, T. Abel, \& C. H. Page (Eds.), Freedom and Control in Modern Society (pp. 18-66). New York: Octagon Books.

McHale, S.M., Crouter, A.C., \& Whiteman, S.D. (2003). The family contexts of gender development in childhood and adolescence. Social Development, 12(1), 125-148.

McPherson, M. (2004). A Blau Space primer: prolegomenon to an ecology of affiliation. Industrial and Corporate Change, 13, 263-280. doi: 10.1093/icc/13.1.263.

McPherson, M., Smith-Lovin, L., \& Cook, J. M. (2001). Birds of a feather: homophily in social networks. Annual Review of Sociology, 27, 415-444.

Moreno, J. L. (1934). Who shall survive? A new approach to the problem of human interrelations. Washington DC: Nervous and Mental Disease Publishing Co.

Pianta, R.C. (1999). Enhancing relationships between children and teachers. Washington DC: American Psychological Association. doi: 10.1037/10314-000. 
Robins, G., Pattison, P., Kalish, Y., and Lusher, D. (2007). An introduction to exponential random graph models for social networks. Social Networks, 29, 169-348. doi: 10.1016/j.socnet.2006.08.002.

Rose-Krasnor, L. (2009). Future directions in youth involvement research. Social Development, 18(2), 497-509. doi: 10.1111/j.1467-9507.2008.00506.x

Schaefer, D.R., Fabes, R.A., Hanish, L.D., \& Martin, C.L. (2010). Fundamental principles of network formation among preschool children. Social Networks, 32, 61-71. doi: 10.1016/j.socnet.2009.04.003

Scott, J. (2000). Social network analysis: A handbook (2 ${ }^{\text {nd }}$ edition). London: Sage Publications.

Seidman, E. (1988). Back to the future, community psychology: Unfolding a theory of social interventions. American Journal of Community Psychology, 16(1), 3-24.

Seidman, E. (1991). Growing up the hard way: Pathways of urban adolescents. American Journal of Community Psychology, 19(2), 173-205.

Seidman, E., Allen, L., Aber, J.L., Mitchell, C., Feinman, J., Yoshikawa, H., Comtois, K.A., Golz, J., Miller, R.L., Ortiz-Torres, B., \& Roper, G.C. (1995). Development and validation of adolescent-perceived microsystem scales: Social support, daily hassles, and involvement. American Journal of Community Psychology, 23, 355-388.

Serpell, Z.N., \& Mashburn, A.J. (2012). Family-school connectedness and children's early social development. Social Development, 21(1), 21-46. doi: 10.1111/j.1467-9507.2011.00623.x.

Simmel, G. (1950 [1908]) Quantitative aspects of the group. In K. H. Wolff (Trans.), The Sociology of Georg Simmel (pp. 87-177). Glencoe, IL: The Free Press.

Simmel, G. (1955 [1922]). The web of group affiliations. In R. Bendix (Trans.), Conflict and the web of group affiliations (pp. 126-195). Glencoe, IL: The Free Press. 
Spillane, J.P., \& Thompson, C.L. (1997). Reconstructing conceptions of local capacity: The local education agency's capacity for ambitious instructional reform. Educational Evaluation and Policy Analysis, 19, 185-203.

Szapocznik, J. \& Coatsworth, J.D. (1999). An ecodevelopmental framework for organizing the influences on drug abuse: A developmental model of risk and protection. In D. Meyer \& C.R. Hartel (Eds.), Drug abuse: Origins and interventions (pp. 331-366). Washington, D.C.: American Psychological Association.

Troop-Gordon, W., \& Kopp, J. (2011). Teacher-child relationship quality and children's peer victimization and aggressive behavior in late childhood. Social Development, 20(3), 536-561. doi: 10.1111/j.1467-9507.2011.00604.x.

Veenstra, R. \& Dijkstra, J.K. (2011). Transformations in adolescent peer networks. In B. Laursen \& W.A. Collins (eds.), Relationship pathways: From adolescence to young adulthood (pp. 135-154). New York: Sage.

Wasserman, S. \& Faust, K. (1994). Social network analysis: Methods and applications. New York: Cambridge University Press.

Wellman, B. (1988) Structural analysis: From method and metaphor to theory and substance. In B. Wellman \& S. D. Berkowitz (eds.), Social structures: a network approach (pp. 19-61). New York: Cambridge University Press. 
Table 1

Nested and Networked Definitions of Ecological Systems Constructs

Construct Nested Networked

(from Bronfenbrenner 1979)

Ecological “...a nested arrangement of structures, each Environment contained within the next.” (p. 22)

Setting

Microsystem

Mesosystem

Exosystem

Macrosystem

Chronosystem "...a place where people can readily engage in face-to-face interaction."

"...a pattern of activities, roles, and interpersonal relations experienced by the developing person in a given setting with particular physical and material characteristics.” (p. 22)

"...the interrelations among two or more settings in which the developing person actively participates." (p. 25)

"... one or more settings that do not involve the developing person as an active participant, but in which events occur that affect, or are affected by, what happens in the setting containing the developing person." (p. 25)

"...consistencies, in the form and content of lower-order systems that exist, or could exist, at the level of subculture or culture as a whole, along with any belief systems or ideology underlying such consistencies." (p. 26)

"...the influence on the person's development of changes (and continuities) over time in the environments in which the person is living." (Bronfenbrenner, 1986b, p. 724) ...an overlapping arrangement of structures, each directly or indirectly connected to the others by the direct and indirect social interactions of their participants.

...a set of people engaged in social interaction, which necessarily occurs in, and is likely affected by the features of, a place.

...a setting - that is, a set of people engaged in social interaction - that includes the focal individual.

...a social interaction between participants in different settings that both include the focal individual.

...a setting - that is, a set of people engaged in social interaction - that does not include, but whose participants interact directly or indirectly with, the focal individual.

...the social patterns that govern the formation and dissolution of social interactions between individuals (e.g. homophily, transitivity, etc.), and thus the relationships among ecological systems.

...the observation that patterns of social interactions between individuals change over time, and that such changes impact the focal individual, both directly and by altering the configuration of ecological systems around him/her. 


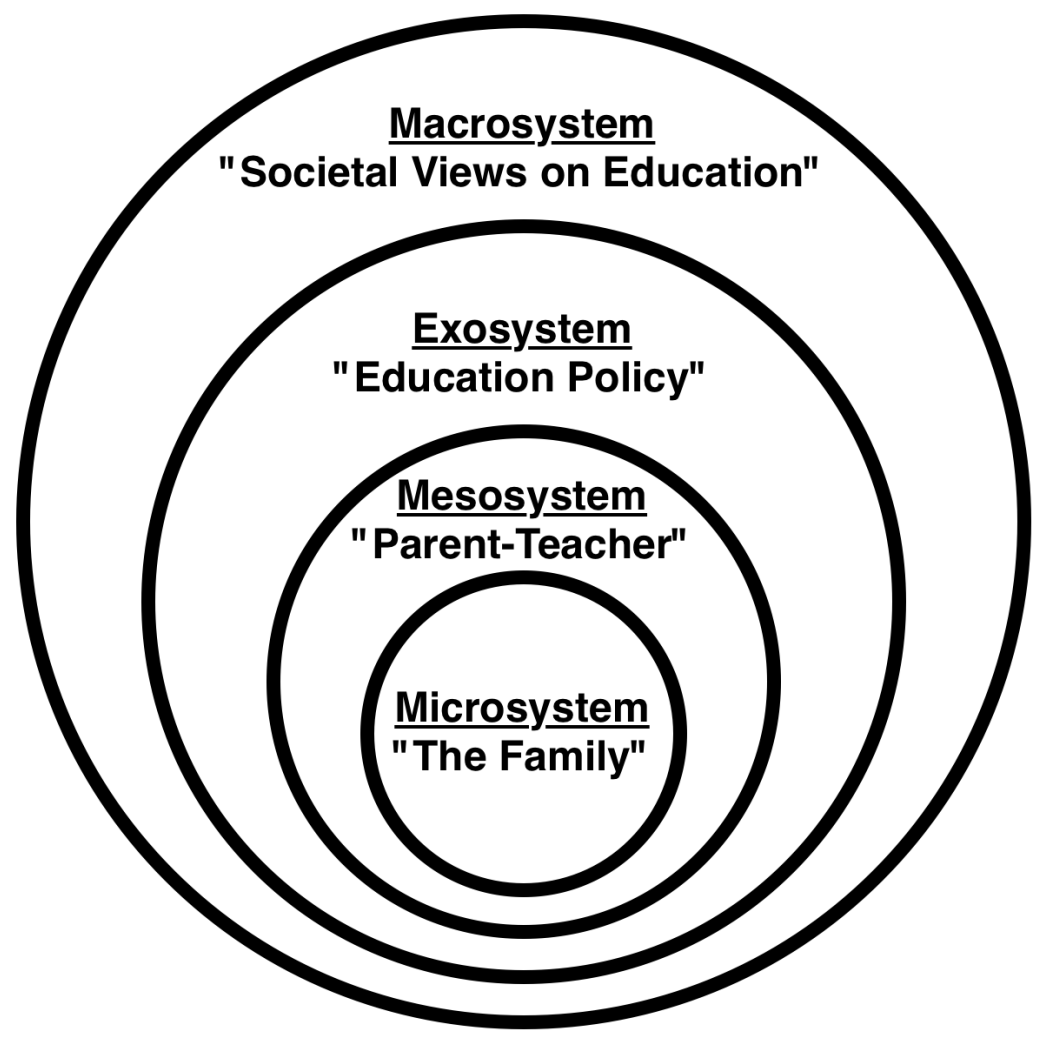

Figure 1. Nested model of ecological systems originally proposed by Bronfenbrenner (1979). 


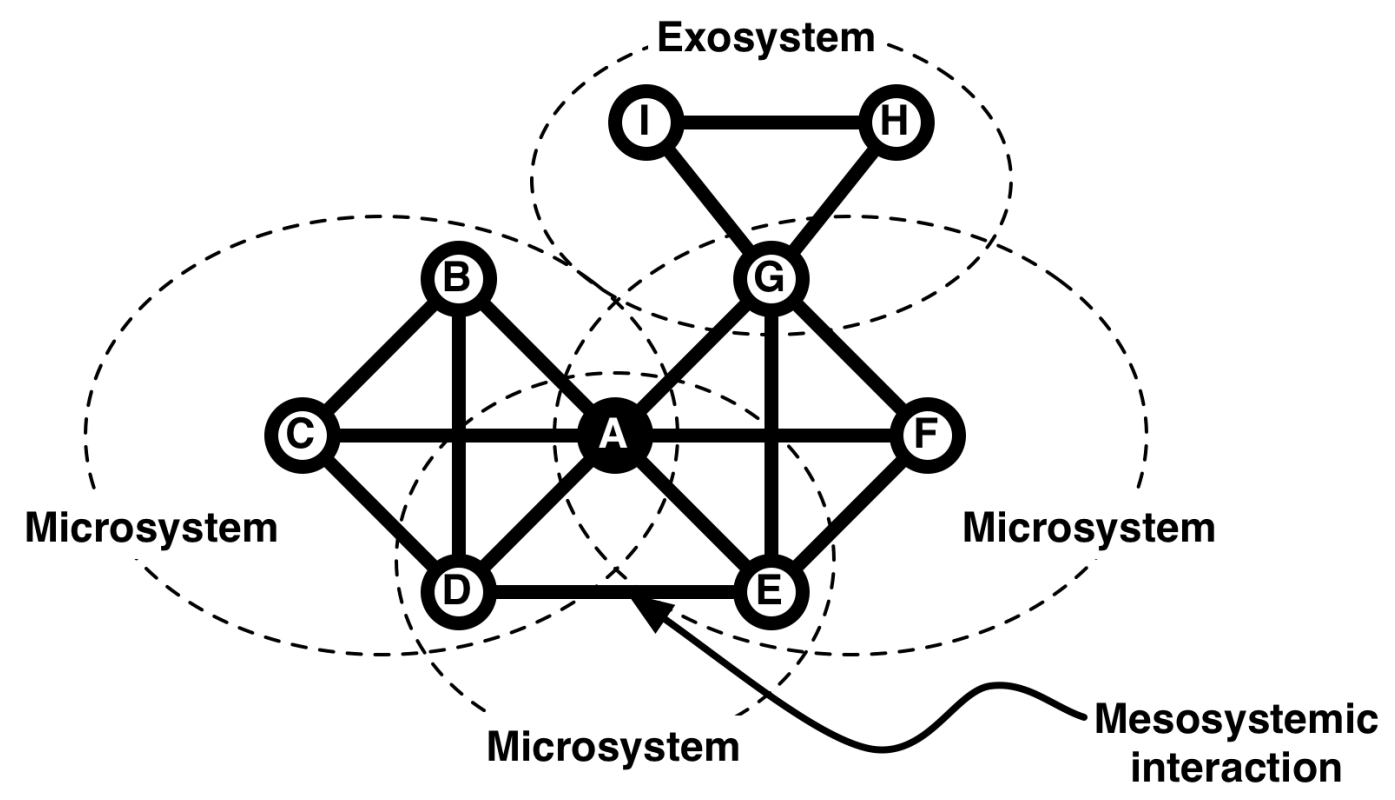

Figure 2. Networked model of ecological systems, focused on person A. 


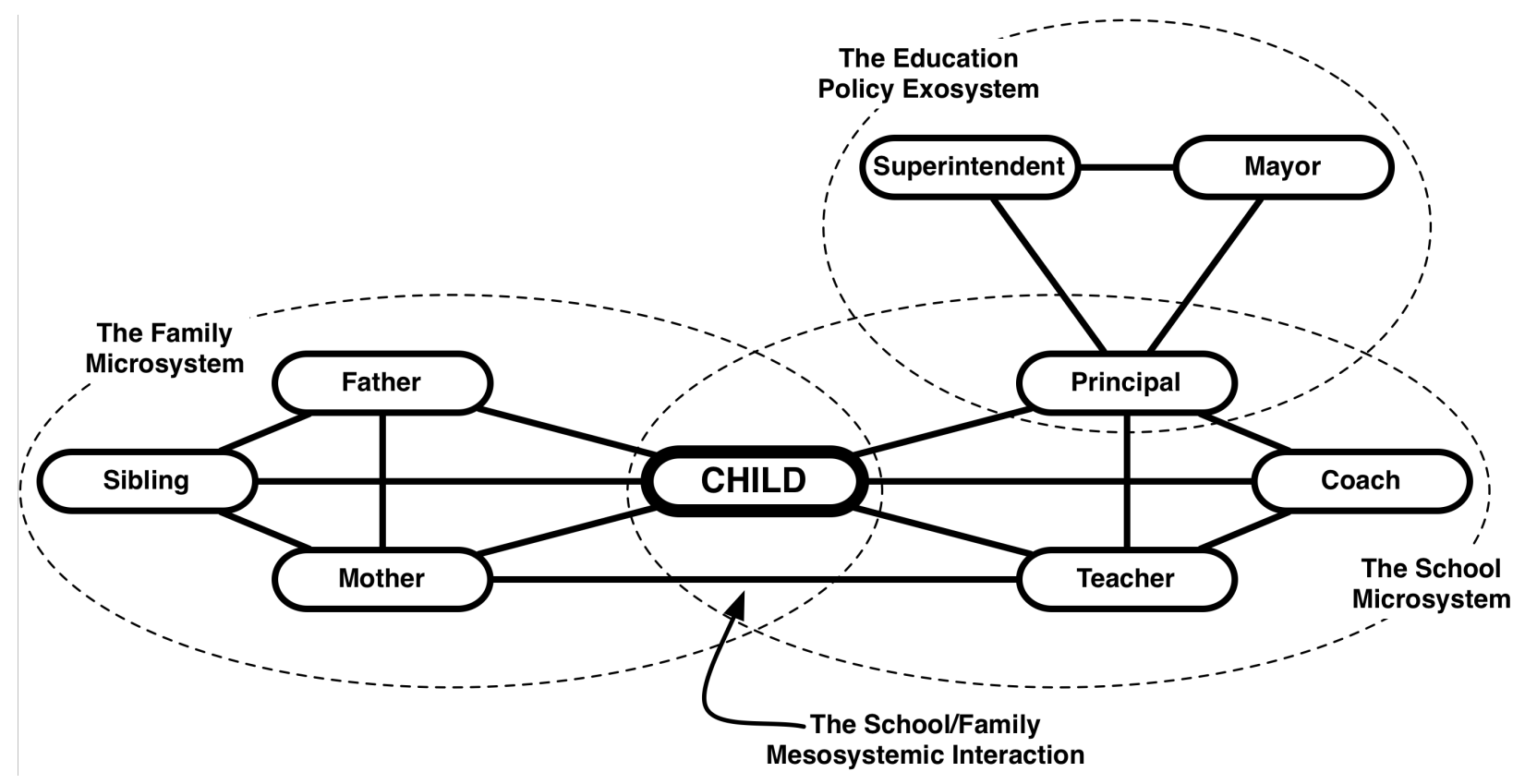

Figure 3. Hypothetical example illustrating a networked model of ecological systems 


\section{All Maximal \\ Complete \\ Subgraphs}

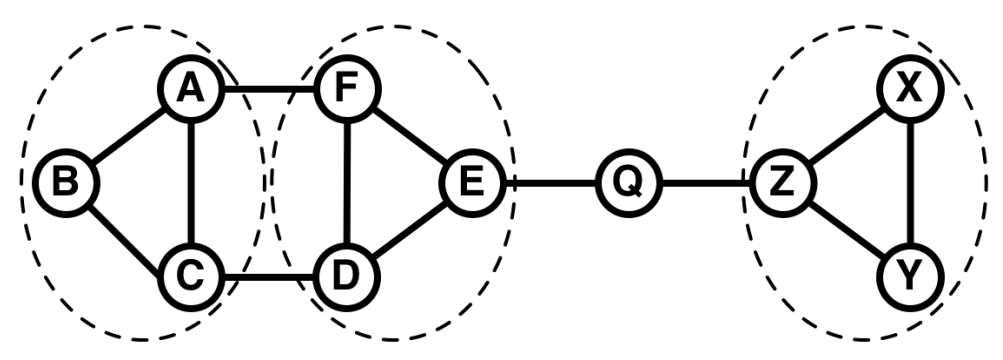

Selected

2-Cliques

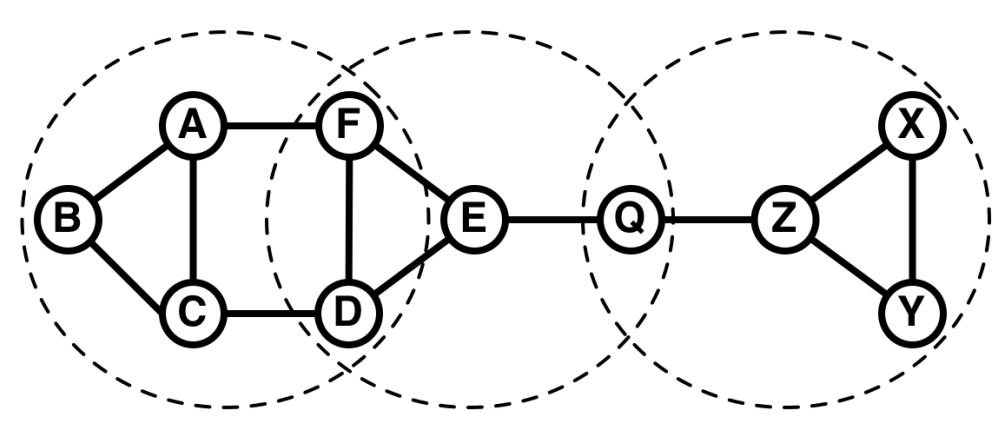

All 2-Cores

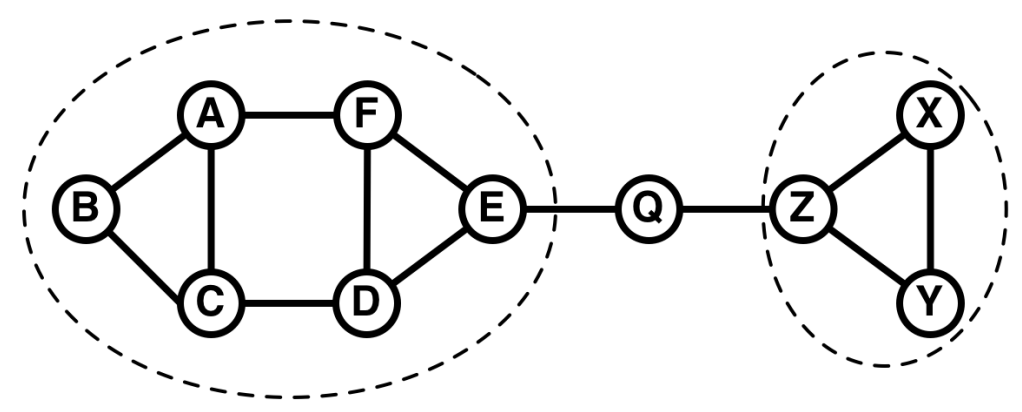

Figure 4. Types of network cliques. 


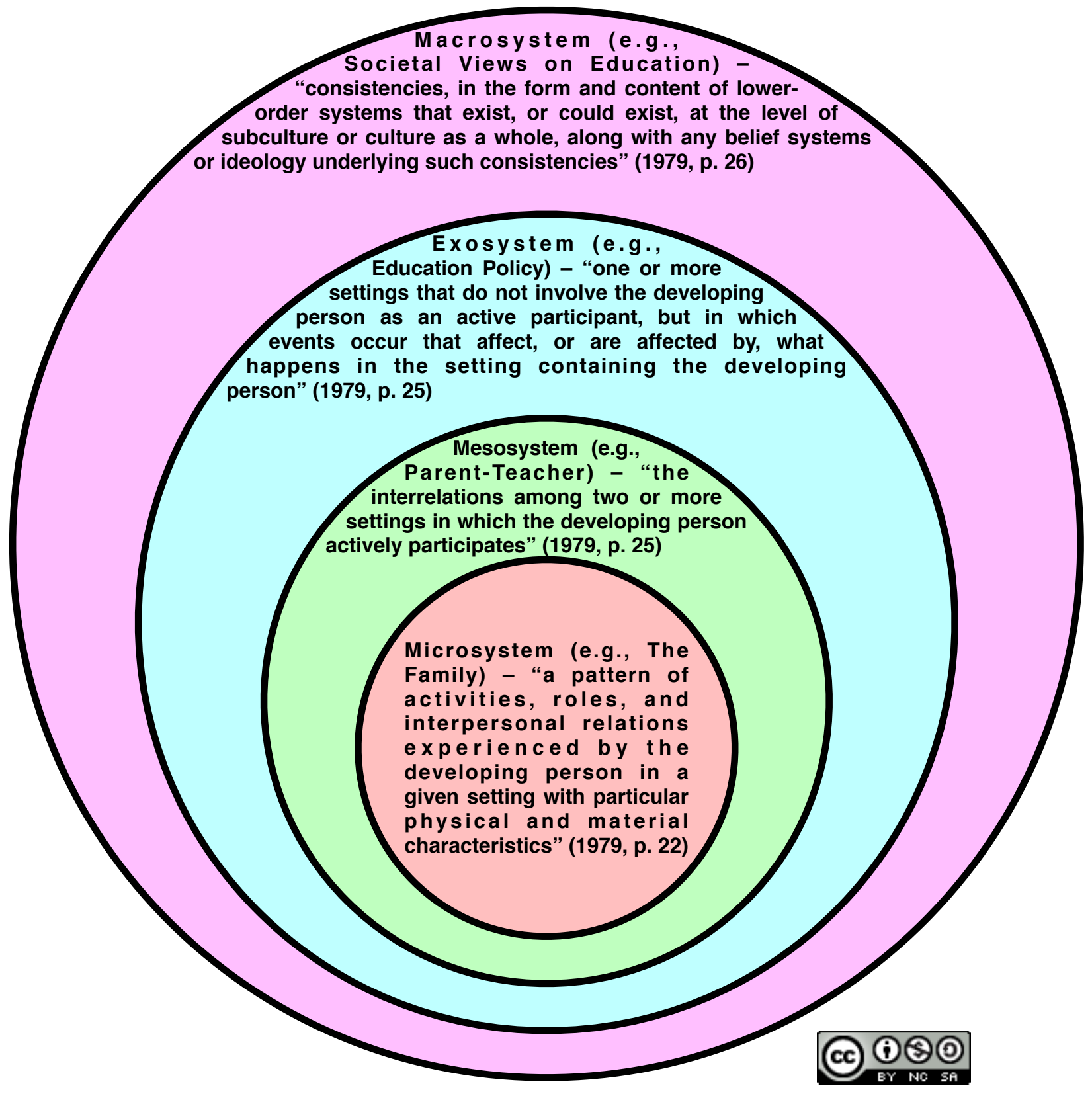

The "Nested" view of an Ecological Environment: “...a nested arrangement of structures each contained within the next” (Bronfenbrenner, 1979, p. 22). Adapted from Neal \& Neal (2013; https://doi.org/10.1111/sode.12018). 


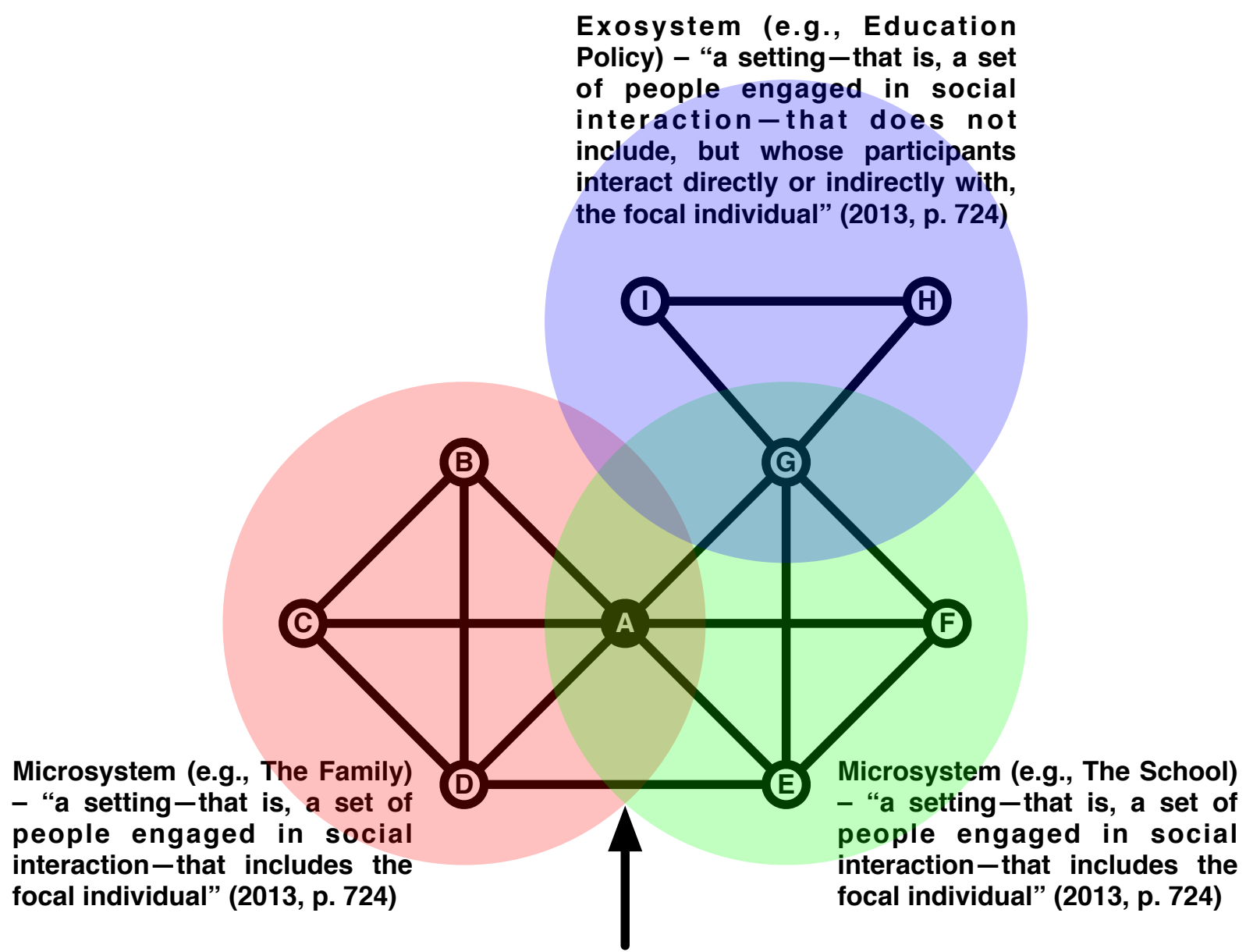

Mesosystemic Interaction (e.g., Family and School) - "a social interaction between participants in different settings that both include the focal individual” (2013, p. 724)

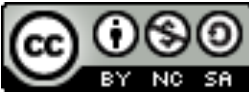

The "Networked" view of an Ecological Environment: “...an overlapping arrangement of structures, each directly or indirectly connected to the others by the direct and indirect social interactions of their participants." Adapted from Neal \& Neal (2013; https://doi.org/10.1111/sode.12018). 